\title{
Observations of nightside auroral plasma upflows in the F-region and topside ionosphere
}

\author{
C. Foster, M. Lester \\ Radio and Space Plasma Physics, Department of Physics and Astronomy, University of Leicester, University Road, \\ Leicester LE1 7RH, UK \\ Received: 3 January 1996/Revised: 22 May 1996/Accepted: 27 May 1996
}

\begin{abstract}
Observations from the special UK EISCAT program UFIS are presented. UFIS is a joint UHF-VHF experiment, designed to make simultaneous measurements of enhanced vertical plasma flows in the F-region and topside ionospheres. Three distinct intervals of upward ion flow were observed. During the first event, upward ion fluxes in excess of $10^{13} \mathrm{~m}^{-2} \mathrm{~s}^{-1}$ were detected, with vertical ion velocities reaching $300 \mathrm{~m} \mathrm{~s}^{-1}$ at $800 \mathrm{~km}$. The upflow was associated with the passage of an auroral arc through the radar field of view. In the F-region, an enhanced and sheared convection electric field on the leading edge of the arc resulted in heating of the ions, whilst at higher altitudes, above the precipitation region, strongly enhanced electron temperatures were observed; such features are commonly associated with the generation of plasma upflows. These observations demonstrate some of the acceleration mechanisms which can exist within the small-scale structure of an auroral arc. A later upflow event was associated with enhanced electron temperatures and only a moderate convection electric field, with no indication of significantly elevated ion temperatures. There was again some evidence of F-region particle precipitation at the time of the upflow, which exhibited vertical ion velocities of similar magnitude to the earlier upflow, suggesting that the behaviour of the electrons might be the dominant factor in this type of event. A third upflow was detected at altitudes above the observing range of the UHF radar, but which was evident in the VHF data from $600 \mathrm{~km}$ upwards. Smaller vertical velocities were observed in this event, which was apparently uncorrelated with any features observed at lower altitudes. Limitations imposed by the experimental conditions inhibit the interpretation of this event, although the upflow was again likely related to topside plasma heating.
\end{abstract}

\section{Introduction}

In recent years, a number of observations of the nightside F-region and topside high-latitude ionosphere have revealed the existence of large upward field-aligned plasma flows. Several authors (e.g. Williams and Jain, 1986; Jones et al., 1988; Winser et al., 1988a, 1989; Wahlund et al., 1992) have reported upflows with velocities ranging from around $100 \mathrm{~m} \mathrm{~s}^{-1}$ to as much as $1500 \mathrm{~m} \mathrm{~s}^{-1}$, with corresponding ion fluxes of up to $10^{14} \mathrm{~m}^{-2} \mathrm{~s}^{-1}$. Satellite observations (e.g. Lockwood, 1982; Heelis et al., 1984; Lu et al., 1992) have also indicated the existence of substantial ion outflows in the high-altitude, high-latitude ionosphere. Upward field-aligned plasma flow has also been linked to the formation of the high-latitude trough (e.g. Williams and Jain, 1986; Winser et al., 1986). Several efforts have been made to model ion outflows (e.g. Wilson, 1994; Loranc and St-Maurice, 1994; Liu et al., 1995; Blelly et al., 1996). Many workers have suggested physical interpretations to account for their observations. Lockwood (1982) attributed Alouette- 1 satellite observations of $\mathrm{O}^{+}$outflows between $400-$ and $1000-\mathrm{km}$ altitude to transverse acceleration of the ions, resulting from heating by ion cyclotron waves, a similar interpretation to that given by Ungstrup et al. (1979). Rocket and satellite observations suggest that such acceleration is generally effective at altitudes above $1000 \mathrm{~km}$, often above auroral arcs, and can generate high-energy (of order $10 \mathrm{eV}$ ) ion outflows. Also within regions of electron precipitation, field-aligned currents can induce low-frequency plasma turbulence, which can lead to increased resistivity and hence enhancements in both the electron temperature and the fieldparallel electric field; each effect can induce significant ion acceleration parallel to the geomagnetic field (e.g. Wahlund et al., 1992, 1993; Forme et al., 1993; Blelly et al., 1996).

At lower ionospheric altitudes, other acceleration mechanisms become important. Winser et al. (1988a) explained observed field-aligned F-region plasma flows of order $100 \mathrm{~m} \mathrm{~s}^{-1}$ in terms of an equatorward neutral wind, thermal expansion of the neutral atmosphere as a result of 
Joule heating, and enhanced ion diffusion. Larger upward fluxes reported by Winser et al. (1988b) and Jones et al. (1988) were similarly explained, including also the effects of transverse acceleration at higher altitudes. Some of the above processes for the generation of upward plasma flow in the high-latitude ionosphere have been reviewed by Rodger et al. (1992). A statistical analysis of field-aligned ion flows, at altitudes between 200 and $500 \mathrm{~km}$, was performed by Keating et al. (1990) using three years of EISCAT CP-1 data, in which an upflow was considered to have occurred if the ion velocity exceeded $100 \mathrm{~m} \mathrm{~s}^{-1}$, or the flux $10^{13} \mathrm{~m}^{-2} \mathrm{~s}^{-2}$. The maximum occurrence of upflows was found to occur at $2100 \mathrm{UT}$, and about $50 \%$ of flows occurred during intervals of elevated ion temperatures, although a greater occurrence of upflows was observed when both ion and electron temperatures were enhanced.

Many ion-upflow events in the high-latitude F-region ionosphere can be characterized according to one of two distinct types, as described by Wahlund et al. (1992). "Type-1" upflows are associated with periods of strong perpendicular electric fields, increased ion temperatures and little electron precipitation, and have been explained in terms of thermal plasma expansion. "Type-2" upflows occur above auroral arcs and are associated with increased electron temperatures and acceleration via electron pressure gradients and field-parallel electric fields. Type- 2 upflows are generally more frequent and exhibit larger parallel ion fluxes than type-1 events (Wahlund $e t$ al., 1992).

This paper presents observations of ion upflows made by the EISCAT incoherent-scatter radar during a 6-h interval when the UK special program UFIS was operated. In the mode employed for this experiment, it was possible to make vertical observations through the $\mathrm{E}$ region to the topside ionosphere. In addition, tristatic UHF measurements were made to determine the electric field components perpendicular to the magnetic field at 315$\mathrm{km}$ altitude. A more detailed description of the SP-UKUFIS program is given in the following section.

Three intervals of transient ion upflows during the 6-h interval are discussed in terms of the possible acceleration mechanisms involved. One event is clearly associated with electron precipitation. F-region observations of an enhanced perpendicular electric field and ion heating are consistent with upward acceleration resulting from thermal plasma expansion; at higher altitudes the upflow is thought to have resulted from electron heating and field-aligned currents. A later event exhibited vertical ion velocities of similar magnitude, again associated with elevated electron temperature, but in this case there was no evidence of significant ion heating. A third event observed above about $600 \mathrm{~km}$ altitude was apparently unaccompanied by lower-altitude upflows, although the vertical field of view cannot provide simultaneous measurements along the same field line at lower altitudes, rendering the experiment insensitive to possible temporal variations within a fieldaligned structure.

These observations illustrate some of the ion-energization processes which can occur at different altitudes within the structure of an auroral arc, and are not inconsistent with the measurements reported by Wahlund et al. (1992, 1993) and with the theoretical work of Blelly et al. (1996).

\section{Experimental configuration}

The UK EISCAT Special Program UFIS was designed to detect upward-flowing ions in the F-region and topside ionosphere, with both the EISCAT UHF and VHF radars taking simultaneous measurements of the high-latitude ionosphere. By necessity, the VHF radar operates at $90^{\circ}$ elevation, and in this experiment the UHF radar also points vertically, to allow for a continuous range of observations from the E-region into the topside ionosphere. A schematic of the experimental configuration is presented as Fig. 1.

In the UHF experiment, pulses of $350 \mu$ s, yielding a height resolution of approximately $31 \mathrm{~km}$, are transmitted on four channels for F-region observations extending over 12 range gates between $150-$ and $500-\mathrm{km}$ altitude. This is the so-called long-pulse scheme. In addition, a 30$\mu$ s power-profile scheme is transmitted for measurements of returned power between $90-$ and $150-\mathrm{km}$ altitude. The remote UHF receiver beams from Kiruna and Sodankylä intersect the Tromsø beam at an altitude of $315 \mathrm{~km}$, enabling the full ion vector velocity to be calculated at this height. The VHF system transmits $750-\mu$ s pulses on two channels for observations in 15 signal gates from 315 to

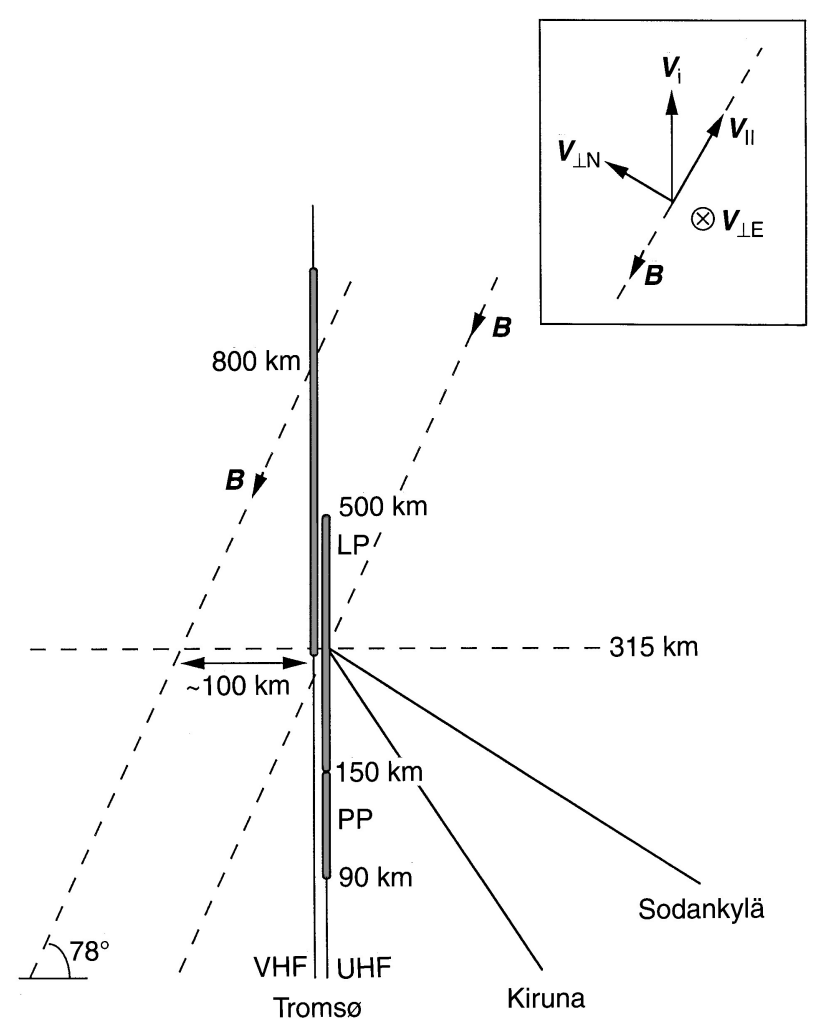

Fig. 1. Schematic showing the configuration of Special UK EISCAT Program UFIS. Shaded areas indicate the altitude ranges of observations of the UHF and VHF radars ( $\mathrm{LP}=$ long pulse, $\mathrm{PP}=$ power profile). Inset shows parallel, perpendicular and vertical components of velocity with respect to the geomagnetic field 
$1260 \mathrm{~km}$, affording a height resolution of approximately $68 \mathrm{~km}$.

\section{Observations - introduction}

The data discussed here are taken from the run of UFIS which commenced at 2100 UT on 17 January 1990 and finished at $0250 \mathrm{UT}$ on the following day. The remote-site UHF data and the Tromsø VHF data have been postintegrated at a resolution of $2 \mathrm{~min}$, whilst the better signalto-noise ratio of the Tromsø UHF data permitted analysis at 1-min resolution. The uncertainties shown in all figures are derived from the formulae of Du Castel and Vasseur (1972).

It should be emphasized that the measured velocities were vertical, and not field aligned. The full ion vector velocity can only be calculated at an altitude of $315 \mathrm{~km}$, where the remote receiver beams intersect the Tromsø UHF beam. However, consideration of the geometry of the system (Fig. 1, inset) reveals that the zonal component of field-perpendicular velocity, $\boldsymbol{V}_{\perp \mathrm{E}}$, can contribute only up to a few $\mathrm{m} \mathrm{s}^{-1}$ to the observed vertical velocity.

The meridional component, $\boldsymbol{V}_{\perp \mathrm{N}}$, has a larger contribution, of about $20 \%$ in the vertical direction, but the fieldparallel velocity component will provide the main part of the vertical velocity. Thus, if the measured value of $\boldsymbol{V}_{\perp N}$ is small relative to the observed vertical velocity, the latter can be interpreted as an indicator of the magnitude of the field-parallel velocity. Furthermore, if the meridional flow were southward then this would contribute to a downward vertical velocity. Thus the vertical velocities presented in Figs. 2a and 3a can be considered representative of field-parallel velocities. However, if $\boldsymbol{V}_{\perp}$ is a function of latitude, and since the perpendicular drift velocities map along magnetic field lines, $\boldsymbol{V}_{\perp}$ may vary along the vertical line of sight, which intersects different field lines at different altitudes (see Fig. 1). The perpendicular velocity measured at $315 \mathrm{~km}$ may not, therefore, be representative of that at higher altitudes if the perpendicular flows vary on spatial extents of less than $100 \mathrm{~km}$.

The ion temperatures measured in this experiment were also vertical. During intervals of enhanced ion flow, the ion-temperature distribution can become anisotropic (Schunk and Walker, 1972; St-Maurice and Schunk, 1973, 1974), with the parallel ion-temperature component being less than the field-perpendicular component. Then, an observed vertical temperature is likely to be an underestimate of the three-dimensional value, the former being principally determined by the field-parallel temperature.

Furthermore, the relative concentration of molecular ions in the F-region can become enhanced during ion frictional heating, a result of increased reaction rates in response to both the elevated effective temperature (StMaurice and Torr, 1978) and the upwelling of the lower atmosphere (Raitt et al., 1975). However, analysis of the data assumed a time-invariant ion composition model, with $\mathrm{O}^{+}$ions dominant above $250-\mathrm{km}$ altitude, which would lead to underestimation of both ion and electron temperatures if a significant proportion of molecular ions were present at F-region peak density altitudes. The limitations of the analysis of incoherent-scatter spectra during intervals of ion frictional heating are addressed in more detail by McCrea et al. (1995) and Davies et al. (1995).

It should be noted that the only parameter derived from the VHF-radar data presented in this paper is the line-of-sight plasma velocity. Unfortunately, the returned VHF spectra were not sufficiently well defined to permit the reliable fitting of ion and electron temperatures. However, the derivation of the line-of-sight plasma velocity was unaffected. To validate the velocities derived from the VHF-radar data, they were compared with those measured by the UHF radar, over the altitude range where both radars observed simultaneously (approximately 315-500 km; see Fig. 1). Within the uncertainties of the parameters, the measured velocities in this altitude range were in agreement. Thus it is believed that the VHF line-of-sight velocity measurements are reliable, up to at least $800-\mathrm{km}$ altitude.

Three intervals of ion upflow observed during this run of SP-UK-UFIS will be discussed in detail. The first, occurring at $2200 \mathrm{UT}$, was associated with ion frictional heating, electron precipitation and elevated electron temperature. The second, observed at 0030 UT, was coincident with soft electron precipitation and enhanced F-region electron temperature. A third upflow, at around 0040 UT, was evident in the VHF data only, again occurring during an interval of F-region particle precipitation but not associated with any other observed effects in the UHF data.

\section{Event 1, observations}

Figure 2a illustrates the line-of-sight plasma velocity for the period 2130-2220 UT measured by the UHF radar at $300-$ and $500-\mathrm{km}$ altitude and by the VHF radar at $800 \mathrm{~km}$. Positive values of velocity indicate upward plasma flow. There is evidence of an upflow maximising at 2200 UT; velocities are positive at all altitudes and increase with height, reaching almost $300 \mathrm{~m} \mathrm{~s}^{-1}$ at $800 \mathrm{~km}$. Measured fluxes at $500-\mathrm{km}$ altitude at this time were around $1.5 \times 10^{13} \mathrm{~m}^{-2} \mathrm{~s}^{-1}$. The event is very short lived, lasting perhaps only $3-4 \mathrm{~min}$, and the velocity maximum occurs at all altitudes simultaneously within the resolution of the data, which have been post-integrated to $1 \mathrm{~min}$.

Vertical ion temperatures at 200-, 300- and 500-km altitude, derived from UHF-radar measurements, are presented in Fig. 2b. An enhancement in ion-temperature peaks at $2200 \mathrm{UT}$ at $300 \mathrm{~km}$, and at $2201 \mathrm{UT}$ at $500 \mathrm{~km}$; it is of approximately 4-min duration, within the temperature enhanced above the typical value by some $800 \mathrm{~K}$ at $300 \mathrm{~km}$, reaching a maximum value of $2000 \mathrm{~K}$ at that altitude. At $500 \mathrm{~km}$ the peak temperature is $2700 \mathrm{~K}$, an enhancement of some $1200 \mathrm{~K}$.

Figure 2c presents the zonal and meridional components of plasma velocity, derived from the tristatic measurements at $315-\mathrm{km}$ altitude. Comparison with the previous figure reveals an excellent temporal correlation between variations in the zonal velocity component (and hence the meridional electric field) and the F-region ion temperature, as expected from previous investigations of 

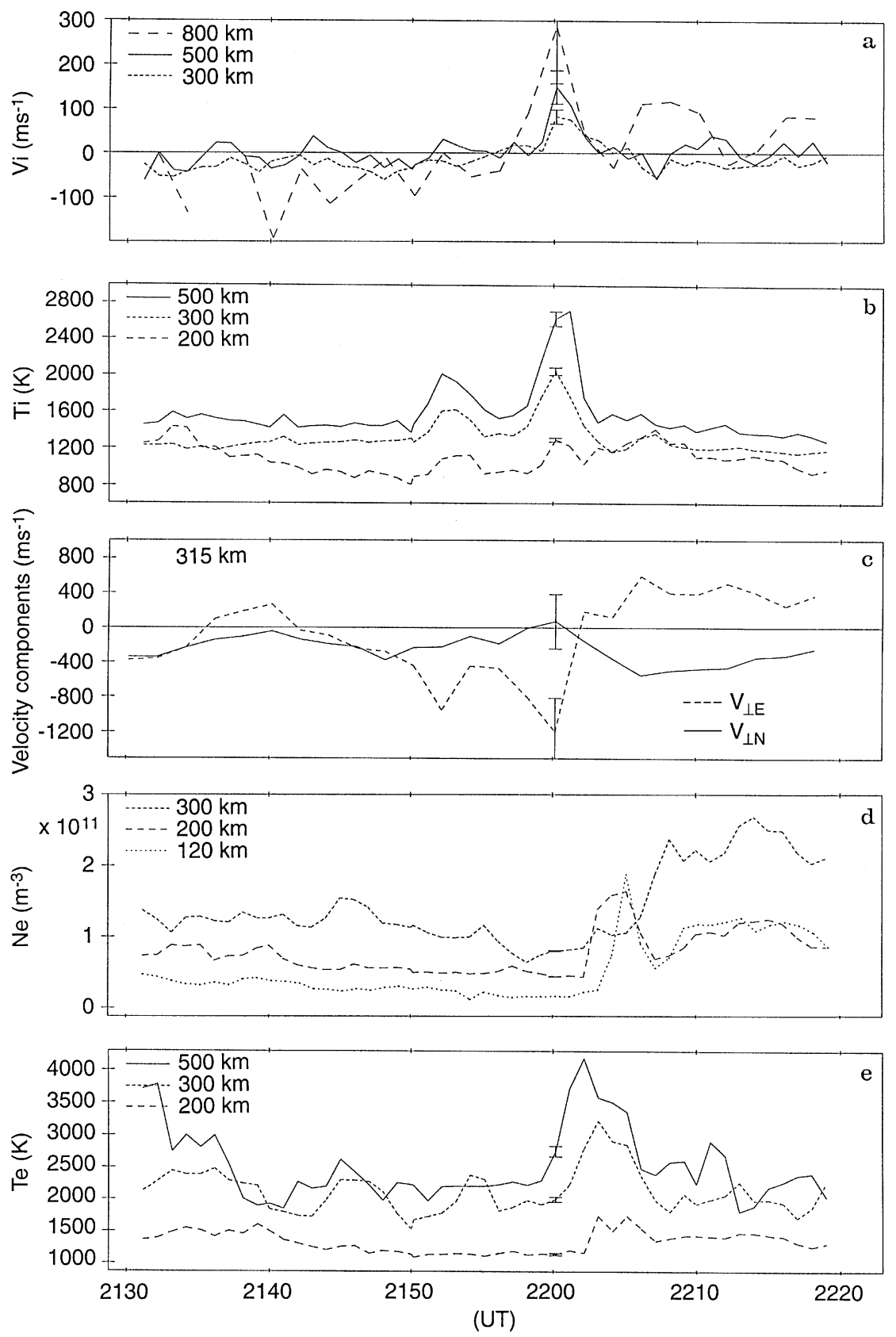

Fig. 2. a EISCAT SP-UK-UFIS UHF ( 300 and $500 \mathrm{~km})$ and VHF $(800 \mathrm{~km})$ measurements of the vertical ion velocity on 17 January 1990. Positive values indicate upward ion flow. b UHF measurements of the vertical ion temperature at 200, 300 and $500 \mathrm{~km}$. c Zonal and meridional components of ion velocity, calculated from UHF tristatic observations at $315-\mathrm{km}$ altitude. d UHF long-pulse (200 and $300 \mathrm{~km})$ and power-profile $(120 \mathrm{~km})$ measurements of electron density. e UHF observations of electron temperature at 200,300 and $500 \mathrm{~km}$. ion frictional heating (e.g. Davies et al., 1995). The plasma velocity reaches a maximum of approximately $1200 \mathrm{~m} \mathrm{~s}^{-1}$ westwards at $2100 \mathrm{UT}$, corresponding to a northward electric field of around $60 \mathrm{mV} \mathrm{m}^{-1}$, simultaneous with the ion-temperature maximum. Following this peak in the plasma velocity, the zonal component changes direction from westwards to eastwards, corresponding to a southward turning of the meridional electric field.

Time-series of electron density at 120, 200 and $300 \mathrm{~km}$ are illustrated in Fig. 2d. It is evident that just prior to and during the upflow at 2200 UT, the F-region electron density is depleted, reducing by perhaps one-third at $300-\mathrm{km}$ altitude. At approximately 2205 UT there is a rapid increase in electron density at lower F-region and E-region altitudes, a signature of particle precipitation. Compari- son of electron density at $200 \mathrm{~km}$ (Fig. 2d) with the velocity components (Fig. 2c) reveals that the eastward turning of the zonal velocity is simultaneous with the onset of the particle precipitation.

The F-region electron temperature at 200, 300 and 500 $\mathrm{km}$ is presented in Fig. 2e. A substantial increase in electron temperature of some $2000 \mathrm{~K}$ is apparent at $500 \mathrm{~km}$, with smaller enhancements at 200 and $300 \mathrm{~km}$, correlating with the reduction in ion velocity and cessation of ion frictional heating, and coincident with the enhancement in the E-region electron density. The maximum electron temperature is seen at 2202 UT at the highest altitude, and about 1 min later at the lower heights.

An enhancement in the zonal ion velocity between 2150 and $2156 \mathrm{UT}$ is also evident (Fig. 2c), which is 
simultaneous with an interval of ion frictional heating (Fig. 2b). Although not as intense as the subsequent event, the ion temperature is increased by some $300-600 \mathrm{~K}$ between 300 and $500 \mathrm{~km}$. However, in this case there is no apparent response at any altitude in the vertical ion velocity (Fig. 2a).

In summary, the interval between 2130 and 2220 UT is marked by an ion upflow at 2200 UT with vertical ion velocities exceeding $300 \mathrm{~m} \mathrm{~s}^{-1}$ at $800-\mathrm{km}$ altitude, and F-region fluxes in excess of $10^{13} \mathrm{~m}^{-2} \mathrm{~s}^{-1}$. The upflow is simultaneous with depleted F-region electron density, strongly enhanced ion temperatures and elevated electric fields. The duration of this event is only $4 \mathrm{~min}$. Immediately following the upflow, electron precipitation into the lower F- and E-regions is observed, accompanied by elevated F-region electron temperatures. An earlier ion-heating event does not have an associated ion upflow.

\section{Event 1, discussion}

The ion-upflow event at 2200 UT appears to be comparable, both in terms of the magnitudes of the observed ion fluxes and in the behaviour of the main plasma parameters, with events described previously (e.g. Wahlund et al., 1992; Winser et al., 1988a, 1989; Jones et al., 1988). In these cases, field-aligned ion velocities of the order of hundreds of $\mathrm{m} \mathrm{s}^{-1}$ at altitudes ranging from 300 to $900 \mathrm{~km}$ were observed in conjunction with enhanced perpendicular electric fields and elevated ion temperatures. Large ionneutral relative velocities perpendicular to the geomagnetic field lead to elevated ion temperatures via frictional heating (e.g. Rees and Walker, 1968; Schunk and Sojka, 1982). Several workers (e.g. Jones et al., 1988, 1992; Wilson, 1994; Rodger et al., 1992) have discussed how this can lead to an enhanced gradient of plasma pressure parallel to the magnetic field, which is capable of driving fieldaligned ion flows with velocities of the order of several hundred $\mathrm{m} \mathrm{s}^{-1}$. Although other acceleration mechanisms have also been proposed (some of which are described in Sect. 1), Jones et al. (1992) concluded that the plasma pressure gradient was the dominant factor in this type of event.

To assess the extent to which pressure gradients might account for the upflow at 2200 UT, field-aligned gradients must be inferred from vertical ones. This assumption is applicable if the feature has a large enough latitudinal extent such that the horizontal temperature distribution is homogeneous, as discussed by Blelly et al. (1996); these authors successfully modelled EISCAT-VHF observations of vertical upflows associated with wide-scale phenomena, events of more than $1 \mathrm{~h}$ duration. Although the upflow at 2200 UT is only a transient feature, the occurrence of maximum ion temperatures and maximum vertical ion velocities at all altitudes simultaneously indicates a feature which "switches on" near 2200 UT, having a latitudinal extent of at least $100 \mathrm{~km}$ (Fig. 1), rather than a small-scale, field-aligned feature moving through the radar field of view. Thus field-parallel gradients might be assumed from vertical observations. With this assumption in mind, the vertical diffusion velocity, resulting solely from plasma pressure gradients, was modelled. Although a simple approach, Jones et al. (1988, 1992) successfully explained similar observations of field-aligned upflows associated with enhanced plasma temperature in terms of pressure gradients alone; the event at 2200 UT was modelled in the same way to provide a more quantitative comparison with their observations. At altitudes above $250 \mathrm{~km}$, however, the pressure gradient at $2200 \mathrm{UT}$ was consistent with downward plasma flow, whereas the observations indicated upward flow at all heights between 150 and $800 \mathrm{~km}$. As discussed previously, composition changes during the upflow may have resulted in an underestimation of the plasma temperature at F-region altitudes, which would in turn affect the calculated pressure gradient. However, simulated increases in the ion and electron temperatures, to correct for possible underestimations, could not produce a vertical pressure gradient consistent with the observed vertical velocity profile. Thus we conclude that the event at 2200 UT cannot be interpreted solely in terms of vertical pressure gradients, suggesting that the upward flows observed between 300and $800-\mathrm{km}$ altitude were not associated with a single feature of large latitudinal extent.

As previously stated, the field-perpendicular plasma velocities have components in the vertical direction, and it is possible that the large vertical flows seen at high altitudes could be the result of enhanced $\boldsymbol{E} \times \boldsymbol{B}$ drift speeds. Assuming a moderate parallel velocity (say $50 \mathrm{~m} \mathrm{~s}^{-1}$ ) at $800-\mathrm{km}$ altitude, and neglecting the vertical component of $\boldsymbol{V}_{\perp \mathrm{E}}$, a northward meridional velocity in excess of $1200 \mathrm{~m} \mathrm{~s}^{-1}$ would be required to produce the observed vertical velocities of some $300 \mathrm{~m} \mathrm{~s}^{-1}$. Such values are unlikely and are never observed at $315 \mathrm{~km}$ in these data.

It seems most likely that a transient event such as that at $2200 \mathrm{UT}$ is associated with an auroral arc. Numerous observations have indicated the occurrence of ion upflows in the vicinity of arcs (e.g. Wahlund et al., 1992; Lu et al., 1995), attributed to a variety of acceleration mechanisms. At F-region altitudes, heating of the electron gas by soft particle precipitation can lead to upward diffusion via thermal plasma expansion (Rodger et al., 1992; Wahlund et al., 1993; Liu et al., 1995). Large convection electric fields are often observed in the vicinity of auroral arcs (Marklund, 1984; Opgenoorth et al., 1990; Lewis et al., 1994), which can also result in enhanced pressure gradients through ion frictional heating, as discussed previously. Satellite and rocket observations of higher-energy outflows, occurring above auroral arcs, have been attributed to transverse ion acceleration by low-frequency waves, such as ion cyclotron waves (Ungstrup et al., 1979; Klumpar, 1979; Heelis et al., 1984; Retterer et al., 1994). These ion conics are generally observed at altitudes above $1000 \mathrm{~km}$, although Whalen et al. (1978) observed such heating at altitudes of 400-500 km. Ion-acoustic instabilities which are unstable to field-aligned currents can lead to enhanced (anomalous) resistivity and significant Joule heating of the electrons (Swift, 1965; Wahlund et al., 1993; Forme et al., 1993). Forme et al. (1993) showed that these instabilities were initiated at altitudes above $1000 \mathrm{~km}$, but conduction could lead to heating at lower altitudes, where classical collisional heating also becomes important. 
Upward ion fluxes can be generated both by the modification of the electron pressure gradient and by enhanced field-parallel electric fields, the latter resulting from the increased resistivity in the presence of field-aligned currents (Wahlund et al., 1992, 1993).

There is indeed evidence of auroral precipitation between 2200 and 2205 UT (Fig. 2), both in the enhancedtopside and F-region electron temperature, and in the increased electron density at 120 - and $200-\mathrm{km}$ altitude. The interval of F-region frictional heating is associated with an elevated perpendicular electric field, which is observed approximately $3 \mathrm{~min}$ prior to the density enhancement and, therefore, apparently situated on the leading edge of the arc. There is no indication of any latitudinal drift of the feature at $2200 \mathrm{UT}$; the enhancement in ion temperature is observed at all heights simultaneously, which is consistent with the small meridional velocity measured at the time. The F-region ion temperature returns to more moderate values between 2200 and 2202 UT, concomitant with a reversal in the zonal velocity from $1200 \mathrm{~m} \mathrm{~s}^{-1}$ westwards to around $200 \mathrm{~m} \mathrm{~s}^{-1}$ eastwards, corresponding to a change from a region of large northward electric field to a moderate $\left(\sim 10 \mathrm{mV} \mathrm{m}^{-1}\right)$ southward field. The timing is such that this southward turning of the electric field is coincident with the enhancement in F-region electron temperature. These observations are consistent with ion heating induced by a convection velocity shear, as discussed by Ganguli et al. (1994). These authors described how strongly sheared flows in the topside ionosphere could generate low-frequency plasma waves, potentially leading to ion heating and thermal ion upflows. The electron heating is seen first at the higher altitudes, indicating an equatorward drift of perhaps $600 \mathrm{~m} \mathrm{~s}^{-1}$; this is greater than the meridional velocity measured at $2200 \mathrm{UT}$ at $315 \mathrm{~km}$, but is similar to velocities measured between 2205 and 2210 UT. The increased ionization is also observed first at $200 \mathrm{~km}$, with higher energy precipitation evident later at $120-\mathrm{km}$ altitude. This again is consistent with an equatorward-drifting field-aligned arc.

It seems therefore probable that the upflow observed at 2200 UT resulted from a combination of processes related to the passage of an auroral arc through the radar beam. The observations indicate that the electron temperature increased with altitude, and that the temperature maximum was evident first at the higher altitudes. Although reliable electron-temperature measurements are not available beyond $500 \mathrm{~km}$, it might be inferred that the electrontemperature maximum at $800 \mathrm{~km}$ occurred between 2200 and 2202 UT at the latitude of EISCAT; that is, at the time of the observed upflow at that altitude. This is in accordance with observations reported by Wahlund et al. (1993), who associated topside ion upflows with transient, high-altitude electron heating resulting from the simultaneous presence of field-aligned currents and ion-acoustic turbulence. These authors also showed that such heating was correlated with electron precipitation in the 100-500$\mathrm{eV}$ energy range, indicated by increased ionization between altitudes of 170 and $230 \mathrm{~km}$. This is also consistent with our observations of elevated topside electron temperature followed by enhanced electron density at $200 \mathrm{~km}$.
Thus we surmise that the upflow observed at $800 \mathrm{~km}$ was related to electron heating above a field-aligned auroral arc, which at 2200 UT was poleward of EISCAT, whilst the upward velocities observed at lower altitude were probably induced by ion heating, probably resulting from the velocity shear and enhanced convection electric field on the equatorward edge of the arc; the geometry is such that the plasma flows along the different field lines were detected simultaneously in the vertical line of sight. The acceleration regions then moved out of the field of view as the arc drifted equatorward, indicated by subsequent Fregion electron heating and enhanced ionization.

Blelly et al. (1996) modelled EISCAT-VHF observations of a large-scale ion upflow by imposing a combination of an enhanced convection electric field and an upward field-aligned current, successfully reproducing the general features of the event. Although this was a long-lived feature (lasting more than $1 \mathrm{~h}$ ), where ion and electron heating were observed simultaneously, the model does not preclude the possibility that transient upflows related to auroral arcs can be generated by the same mechanisms. Indeed, it is possible that the event presented here was long lived, but only observed for a few minutes as it passed through the EISCAT beam.

Finally, it is noted that the zonal drift velocity turned eastward just prior to 2140 UT. However, between 2142 and 2202 UT, westward flow was then observed. This pattern of flow is put into a wider spatial context by observations during this interval from the EISCAT magnetometer cross. An eastward electrojet was apparent between about 2140 and $2200 \mathrm{UT}$, consistent with the westward flow measured by the EISCAT radars. At 2200 UT a substorm-enhanced westward electrojet was detected in the magnetometer data. These observations are also consistent with the eastward flow and electron precipitation detected by the EISCAT radars from 2200 UT.

In summary, this event exhibits characteristics which are common to both the type- 1 and type- 2 upflows described by Wahlund et al. (1992), with the presence of F-region upflows related to enhanced electric fields and ion frictional heating, and higher-altitude, greater-magnitude upward velocities associated with field-aligned currents and enhanced electron temperatures. The F-region and topside upflows observed here are probably not directly related to one another, since the acceleration occurs along different field lines; this event is indicative of the different acceleration regions which can exist within the structure of an auroral arc.

\section{Event 2, observations}

Figure 3 displays data from SP-UK-UFIS for the interval 0020-0100 UT on 18 January 1990. The vertical ion velocity measured at 350,500 and $800 \mathrm{~km}$ is illustrated in Fig. 3a. An upflow was observed between 0028 and $0034 \mathrm{UT}$, the vertical ion velocity increasing with altitude from less than $100 \mathrm{~m} \mathrm{~s}^{-1}$ at $350 \mathrm{~km}$ to some $300 \mathrm{~m} \mathrm{~s}^{-1}$ at $800 \mathrm{~km}$. Vertical ion fluxes were somewhat greater than in the previous event, reaching some $5 \times 10^{13} \mathrm{~m}^{-2} \mathrm{~s}^{-1}$ at 

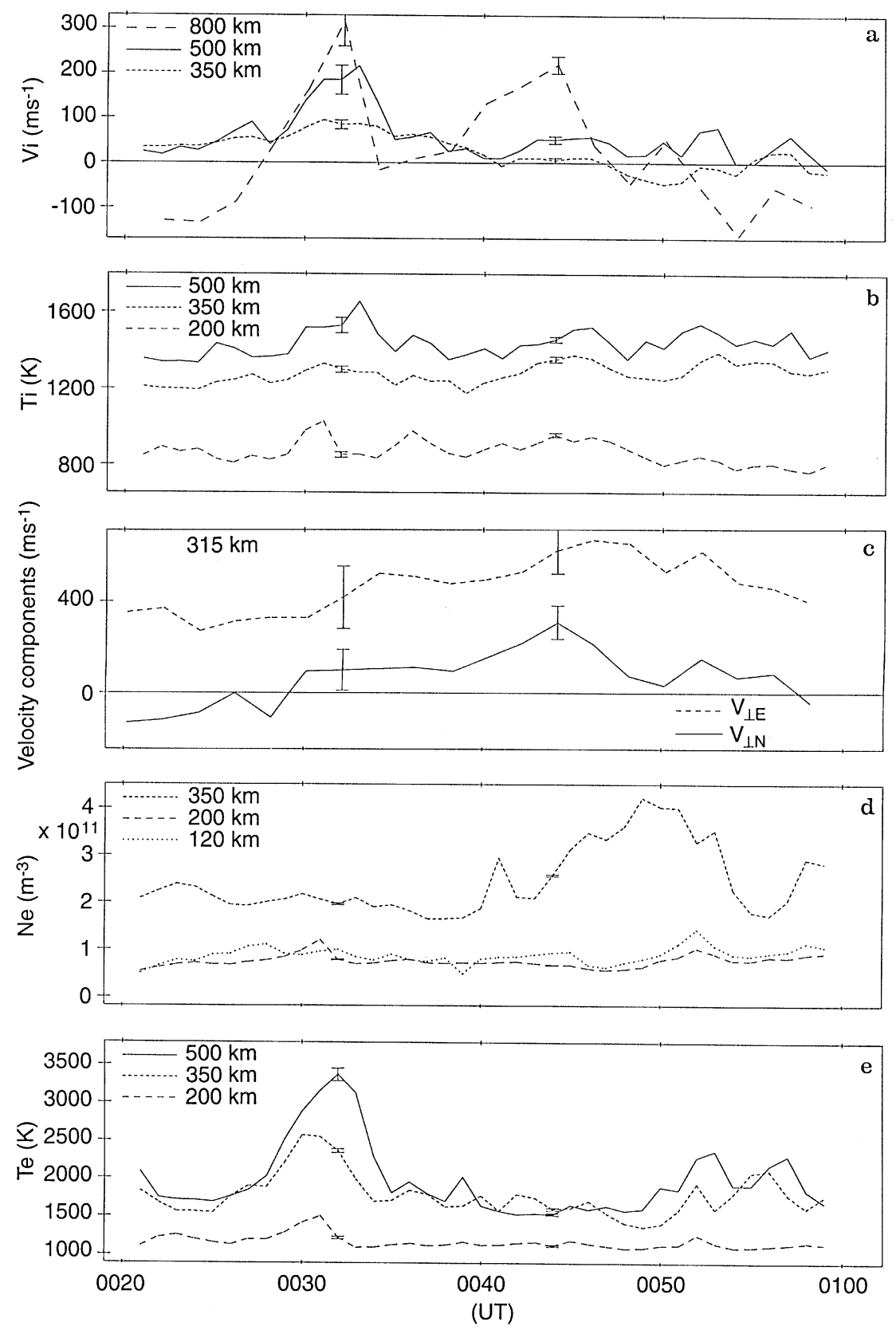

Fig. 3. Same as Fig. 2 but for $0020-0130$ UT on 18 January 1990

500-km altitude. Figure 3c reveals zonal and meridional flows measured at $315 \mathrm{~km}$ which are equivalent to perpendicular electric fields of less than $30 \mathrm{mV} \mathrm{m}^{-1}$. The southward to northward turning of the meridional velocity is equivalent to a change in electric field of only approximately $10 \mathrm{mV} \mathrm{m}^{-1}$. There is correspondingly little indication of frictional heating of the ion population (Fig. 3b); no enhancements in ion temperature are seen at $350 \mathrm{~km}$, although at 200 and $500 \mathrm{~km}$ there are peak increases of perhaps $300 \mathrm{~K}$, separated by $2 \mathrm{~min}$, with that at $500 \mathrm{~km}$ simultaneous with the maximum ion velocity at that altitude. There is a good correlation between the vertical ion velocity and an enhancement in the F-region electron temperature, at least at $500 \mathrm{~km}$, where a temperature increase of some $1500 \mathrm{~K}$ is evident, as illustrated in Fig. 3e.
The electron density (Fig. 3d) is relatively high throughout the entire period from 0020 to 0100 UT; comparison with electron densities at $120 \mathrm{~km}$ between 2140 and $2200 \mathrm{UT}$ (Fig. 2d) reveals around a fourfold increase during the second period. This high level of ionization is indicative of production by electron precipitation, which between 0020 and 0040 UT appears to be rather diffuse, with perhaps a discrete peak evident at 0031 UT at $120 \mathrm{~km}$.

In contrast to the earlier event, the upflow at $0030 \mathrm{UT}$ is observed simultaneously with an interval of enhanced F-region electron temperature, with only moderate perpendicular electric fields and little ion heating. Although the maximum observed vertical velocities are similar in each event, the second exhibits larger upward fluxes; this event occurs during a period of relatively high electron 
density indicative of diffuse particle precipitation, in contrast to the more discrete feature seen following the upflow at 2200 UT.

\section{Event 2, discussion}

In terms of the magnitude of the maximum vertical ion velocity and the duration of the event, the upflow observed around $0030 \mathrm{UT}$ is comparable with the earlier feature. However, in this case we observe only modest increases in the vertical ion temperature during the upflow, which is consistent with the moderate measured convection velocities. Furthermore, in the earlier event the electron temperature at the lower altitudes was seen to increase subsequent to the upflow, whereas here there appears to be a direct correlation between enhanced electron temperature and vertical ion velocity at $500-\mathrm{km}$ altitude. The electron heating might be due to a downward heatflux of magnetospheric origin, or the result of particle precipitation; evidence of a discrete feature is apparent as a slight increase in electron density at $200 \mathrm{~km}$, and there is certainly a correlation between this and enhancements in both ion and electron temperatures at that altitude. It has previously been discussed how particle precipitation can result in enhanced F-region and topside electron temperatures, which can induce upward plasma acceleration via thermal diffusion and enhanced field-parallel electric fields. Again, temperature measurements above $500-\mathrm{km}$ altitude are not available, but we might infer elevated temperatures above this range from the observations at the lower altitudes. Thus we conclude that the observed upflows were associated with precipitation-induced electron heating in the F-region and topside ionosphere. It is interesting that in this event enhanced electron temperatures at $500 \mathrm{~km}$ were accompanied by large vertical velocities at the same altitude, whereas in the previous event somewhat greater electron temperatures at 300 and $500 \mathrm{~km}$ were not coincident with upward flows. The reason for this is not readily apparent, but it might simply be due to differences in field-aligned pressure gradients between the two events, which cannot be quantitatively examined from vertical observations for such transient features.

Several aspects of this event are suggestive of a fieldaligned feature moving first equatorward into the vertical field of view and then poleward. Examination of the velocity time-series reveals that the vertical velocity is seen to increase first at the highest altitude. Similarly, the electron temperature appears to increase first at the higher altitudes; this is consistent with the southward meridional velocity measured just prior to the event. Concurrent with the onset of the electron heating, however, the meridional convection velocity turned northward, and consequently the electron temperature is seen to reduce first at the lower altitudes as the feature moves poleward away from the radar field of view.

In summary, the enhanced electron temperatures and moderate perpendicular electric fields associated with this upflow event make it characteristic of the type-2 upflow described by Wahlund et al. (1992). Similar observations of enhanced topside electron temperatures were documented by Wahlund et al. (1993), and were attributed to heating resulting primarily from enhanced resistivity due to precipitation-induced ion-acoustic turbulence. It is interesting to compare this event with that observed at 2200 UT, when upflows of similar magnitude were associated with both enhanced ion and electron temperatures. Although the experimental configuration does not allow for a quantitative assessment of the acceleration mechanisms involved in each case, these two events exhibit characteristics consistent with the most commonly considered acceleration processes which can lead to F-region and topside ion upflows.

\section{Event 3, observations}

A third ion upflow is evident between 0038 and 0046 UT (Fig. 3a). This event is markedly different from the previous two, in that large upward velocities were seen only in data from the VHF radar. Moderate vertical ion velocities, of less than $50 \mathrm{~m} \mathrm{~s}^{-1}$, were observed up to $500 \mathrm{~km}$ by both UHF and VHF radars. Enhanced upward flows were evident from $600-\mathrm{km}$ altitude, exceeding $200 \mathrm{~m} \mathrm{~s}^{-1}$ at $0044 \mathrm{UT}$ at an altitude of $800 \mathrm{~km}$. There is no evidence of ion heating at F-region altitudes during this upflow (Fig. 3b). Slight increases in the zonal and meridional ion velocities are evident (Fig. 3c), although the perpendicular electric field attains a maximum of perhaps only $35 \mathrm{mV} \mathrm{m}^{-1}$. The F-region electron temperature exhibits no response at the time of the upflow (Fig. 3e). However, a transient increase in electron density at $350-\mathrm{km}$ altitude is evident during the event, with a more sustained and substantial enhancement following the upflow (Fig. 3d). As noted previously, there is evidence of diffuse precipitation into the lower F- and E-regions throughout the entire period from 0020 to $0100 \mathrm{UT}$.

In summary, the third upflow observed in this data set differs from the previous two in that it occurred beyond the observing range of the UHF radar, and was detected only by the VHF radar at altitudes above $600 \mathrm{~km}$. Furthermore, the maximum observed velocities were of the order of $200 \mathrm{~m} \mathrm{~s}^{-1}$, some $100 \mathrm{~m} \mathrm{~s}^{-1}$ less than was seen in the other events at the same altitude. Of the earlier two ion upflows, one was associated with enhanced ion and electron temperatures, the other with elevated electron temperatures alone; however, the upflow at 0044 UT was apparently uncorrelated with any temperature variations at lower altitudes.

\section{Event 3, discussion}

The moderate vertical velocities near the F-region peak measured during this event are consistent with the undisturbed ion and electron temperatures at these altitudes. It is possible that the upflow at $600 \mathrm{~km}$ is the result of downward heatflow into the topside, leaving the electron temperature unaffected at lower heights. The heating could also be related to soft particle precipitation; just prior to the maximum observed velocity, an ionization 
peak is apparent at $350 \mathrm{~km}$. However, this was not detected below about $300-\mathrm{km}$ altitude, which is suggestive of precipitation with a maximum energy below the range associated with bulk electron heating at high altitudes (Wahlund et al., 1993).

A further possibility is that the upflow was associated with a field-aligned feature present at higher latitudes. Enhanced field-aligned plasma flows, translated into large vertical velocities, might then be detected only at high altitudes within the VHF-radar field of view (see Fig. 1). Such an interpretation must remain purely speculative, since, without observations away from the radar field of view, the effects of spatial and temporal variations cannot be fully resolved. This highlights one of the limitations of single-pointing-direction experiments such as UFIS, which, although offering measurements at high temporal resolution, yield relatively little spatial information.

\section{Summary and conclusions}

Observations from a 6 -h run of the special UK EISCAT program UFIS have been presented, detailing three distinct intervals of upward ion flow from the F-region ionosphere. At 2200 UT, simultaneous UHF and VHF measurements indicated that the vertical ion velocity increased steadily with altitude from the F-region into the topside ionosphere, attaining flow speeds of approximately $300 \mathrm{~m} \mathrm{~s}^{-1}$, with fluxes of the order of $10^{13} \mathrm{~m}^{-2} \mathrm{~s}^{-1}$. The F-region upflow was simultaneous with a period of ion frictional heating, the result of an enhanced and sheared convection electric field on the edge of an auroral arc; at higher altitudes, the upward flow was thought to be related to elevated electron temperatures and field-aligned currents. Thus the event was reminiscent of both the type- 1 and type- 2 upflows described by Wahlund et al. (1992), and perhaps also of the large-scale features modelled by Blelly et al. (1996). These observations demonstrate some of the features that can exist within the structure of an auroral arc and which can induce upward plasma flow in the F-region and topside ionosphere.

Similar upward ion fluxes were observed at $0030 \mathrm{UT}$. In this case, the upflow was associated with enhanced electron temperatures, moderate convection flows and Fregion particle precipitation. These features are characteristic of the type-2 upflow of Wahlund et al. (1992), discussed in further detail by Wahlund et al. (1993), in which topside electron heating is attributed to enhanced resistivity due to low-frequency turbulence induced by fieldaligned currents. Upward ion acceleration can result from both increased pressure gradients and enhanced fieldaligned electric fields.

Finally, an upflow was detected at altitudes above the observing range of the UHF radar, but which was evident in the VHF data from $600 \mathrm{~km}$ upwards. Smaller vertical velocities were observed in this event, which was apparently uncorrelated with any features observed at lower altitudes. Limitations imposed by the experimental conditions inhibit the interpretation of this event, although the upflow was again likely related to topside plasma heating.
This data set, although limited, gives an indication of the variety of characteristics of ion upflow events, and the diversity of accelerating mechanisms involved. Three distinct events from this single 6-h run of SP-UK-UFIS were presented. The simultaneous operation of the UHF-tristatic and VHF radars, with both transmitters observing along a vertical line of sight, allowed for the direct comparison of observations from E-region altitudes up into the topside ionosphere. However, there are spatial and temporal ambiguities inherent in any single-pointing experiment such as UFIS. The interpretation of line-of-sight measurements in terms of field-parallel features is hindered when transient, field-aligned features are observed in the vertical field of view necessary for the VHF radar. Also, although good temporal resolution is achieved, no direct measurements are obtained from regions beyond the field of view of the radar, thus limiting the information available concerning the spatial evolution of features associated with the ion upflows. In the future, velocity observations from the Superdarn CUTLASS radar (Greenwald et al., 1995) may enable these single-pointing observations to be placed in a wider spatial context.

Acknowledgements. We thank Dr Hermann Lühr for provision of the EISCAT magnetometer cross data. Thanks are also extended to the Director and Staff of EISCAT for providing the data used in this paper. EISCAT is an international facility supported by the national science councils of Finland, France, Germany, Norway, Sweden and the United Kingdom. C. Foster is supported by a studentship from the Particle Physics and Astronomy Research Council of the United Kingdom.

Topical Editor D. Alcaydé thanks J. L. Horwitz and another referee for their help in evaluating this paper.

\section{References}

Blelly, P. L., A. Robineau, and D. Alcaydé, Numerical modelling of intermittent ion outflow events above EISCAT, J. Atmos. Terr. Phys., 58, 273, 1996.

Davies, J. A., M. Lester, B. Jenkins, and R. J. Moffet, Dayside ion frictional heating: EISCAT observations and comparison with model results, J. Atmos. Terr. Phys., 57, 775, 1995.

Du Castel, F., and G. Vasseur, Evaluation des performances d'un sondeur ionesphérique a diffusion incohérent, Ann. Telecommun., 27, 239, 1972.

Forme, F. R. E., J. -E. Wahlund, H. J. Opgenoorth, M. A. L. Persson, and E. V. Mishin, Effects of current driven instabilities on the ion and electron temperatures in the topside ionosphere, J. Atmos. Terr. Phys., 55, 647, 1993.

Ganguli, G., M. J. Keskinen, H. Romero, R. Heelis, T. Moore and C. Pollock, Coupling of microprocesses and macroprocesses due to velocity shear: An application to the low-altitude ionosphere, J. Geophys. Res., 99, 8873, 1994.

Greenwald, R. A., K. B. Baker, J. R. Dudeney, M. Pinnock, T. B. Jones, E. C. Thomas, J.-P. Villain, J.-C. Cerisier, C. Senior, C. Hanuise, R. D. Hunsucker, G. Sofko, J. Koehler, E. Nielsen, R. Pellinen, A. D. M. Walker, N. Sato, and H. Yamagishi, DARN/SUPERDARN: A Global View of the Dynamics of High-Latitude Convection, Space Sci. Rev., 71, 761, 1995.

Heelis, R. A., J. D. Winningham, M. Sugiura, and N. C. Maynard, Particle acceleration parallel and perpendicular to the magnetic field observed by DE-2, J. Geophys. Res., 89, 3893, 1984.

Jones, G. O. L., P. J. S. Williams, K. J. Winser, M. Lockwood, and K. Suvanto, Large plasma velocities along the magnetic field line in the auroral zone, Nature, 336, 231, 1988. 
Jones, G. O. L., P. J. S. Williams, and K. J. Winser, Large ionospheric plasma flows along magnetic field lines: EISCAT observations and their interpretation, Adv. Space Res., 12, 157, 1992.

Keating, J. G., F. J. Mulligan, D. B. Doyle, K. J. Winser, and M. Lockwood, A statistical study of large field-aligned flows of thermal ions at high latitudes, Planet. Space Sci. 9, 1187, 1990.

Klumpar, D. M., Transversely accelerated ions: an ionospheric source of hot magnetospheric ions, J. Geophys. Res., 84, 4229, 1979.

Lewis, R. V., P. J. S. Williams, G. O. L. Jones, H. J. Opgenoorth, and M. A. L. Persson, The electrodynamics of a drifting auroral arc, Ann. Geophysicae, 12, 478, 1994.

Liu, C., J. L. Horwitz, and P. J. Richards, Effects of ion heating and soft-electron precipitation on high-latitude F-region upflows, Geophys. Res. Lett., 22, 2713, 1995.

Lockwood, M., Thermal ion flows in the topside auroral ionosphere and the effects of low-altitude, transverse acceleration, Planet. Space Sci., 30, 595, 1982.

Loranc, M., and J.-P. St-Maurice, A time-dependent gyrokinetic model of thermal ion upflows in the high-latitude $\mathrm{F}$ region, $J$. Geophys. Res., 99, 17429, 1994.

Lu, G., P. H. Reiff, T. E. Moore, and R. A. Heelis, Upflowing ionospheric ions in the auroral region, J. Geophys. Res., 97, 16855,1992

Marklund, G., Auroral arc classification scheme based on the observed arc-associated electric field pattern, Planet. Space Sci., 32, 193, 1984

McCrea, I. W., G. O. L. Jones, and M. Lester, The BEAN experiment - An EISCAT study of ion temperature anisotropies, Ann. Geophysicae, 13, 177, 1995.

Opgenoorth, H. J., I. Häggström, P. J. S. Williams, and G. O. L. Jones, Regions of strongly enhanced perpendicular electric fields adjacent to auroral arcs, J. Atmos. Terr. Phys., 52, 449, 1990.

Raitt, W. J., U. von Zahn, and P. Christopherson, A comparison of thermospheric neutral gas heating and related energetic plasma phenomena at high latitudes during geomagnetic disturbances, J. Geophys. Res., 80, 2277, 1975.

Rees, M. H., and J. C. G. Walker, Ion and electron heating by auroral electric fields, Ann. Geophysicae, 24, 293, 1968.

Retterer, J. M., T. Chang, and J. R. Jaspere, Transversely accelerated ions in the topside ionosphere, J. Geophys. Res., 99, 13189, 1994.

Rodger, A. S., R. J. Moffet, and S. Quegan, The role of ion drift in the formation of ionization troughs in the mid- and high-latitude ionosphere - a review, J. Atmos. Terr. Phys., 54, 1, 1992.
Schunk, R. W., and J. J. Sojka, Ion temperature variation in the daytime high-latitude F region, J. Geophys. Res., 87, 5169, 1982.

Schunk, R. W., and J. C. G. Walker, Ion velocity distributions in the auroral ionosphere, Planet. Space Sci., 20, 581, 1972.

St-Maurice, J.-P., and R. W. Schunk, Auroral ion velocity distributions using a relaxation model, Planet. Space Sci., 22, 1115, 1973.

St-Maurice, J.-P., and R. W. Schunk, Behaviour of ion velocity distributions for a simple collisional model, Planet. Space Sci., 22, $1,1974$.

St-Maurice, J.-P., and D. G. Torr, Nonthermal rate coefficients in the ionosphere: The reactions of $\mathrm{O}^{+}$with $\mathrm{N}_{2}, \mathrm{O}_{2}$ and $\mathrm{NO}$, J. Geophys. Res., 83, 969, 1978.

Swift, D. W., A mechanism for energizing electrons in the magnetosphere, J. Geophys. Res., 70, 3061, 1965.

Ungstrup, E., D. M. Klumpar, and W. J. Heikkila, Heating of ions to superthermal energies in the topside ionosphere by electrostatic ion cyclotron waves, J. Geophys. Res., 84, 4289, 1979.

Wahlund, J.-E., H. J. Opgenoorth, I. Häggström, K. J. Winser, and G. O. L. Jones, EISCAT observations of topside ionospheric ion outflows during auroral activity: revisited, J. Geophys. Res., 97, 3019, 1992

Wahlund, J.-E., H. J. Opgenoorth, F. R. E. Forme, M. A. L. Persson, I. Häggström, and J. Lilensten, Electron energization in the topside auroral ionosphere: on the importance of ion-acoustic turbulence, J. Atmos. Terr. Phys., 55, 623, 1993.

Whalen, B. A., W. Bernstein, and P. W. Daly, Low-altitude acceleration of ionospheric ions, Geophys. Res. Lett., 5, 55, 1978.

Williams, P. J. S., and A. R. Jain, Observations of the high-latitude trough using EISCAT, J. Atmos. Terr. Phys., 48, 423, 1986.

Wilson, G. R., Kinetic modelling of $\mathrm{O}^{+}$upflows resulting from $\boldsymbol{E} \times \boldsymbol{B}$ convection heating in the high-latitude F-region ionosphere, J. Geophys. Res., 99, 17453, 1994.

Winser, K. J., G. O. L. Jones, and P. J. S. Williams, A quantitative study of the high-latitude ionospheric trough using EISCAT's common programmes, J. Atmos. Terr. Phys., 48, 893, 1986.

Winser, K. J., G. O. L. Jones, and P. J. S. Williams, Large fieldaligned velocities observed by EISCAT, J. Atmos. Terr. Phys., 50, 379, 1988a.

Winser, K. J., G. O. L. Jones, and P. J. S. Williams, Variations in field-aligned plasma velocity with altitude and latitude in the auroral zone; EISCAT observations and the physical interpretation, Physica Scripta, 37, 640, 1988b.

Winser, K. J., G. O. L. Jones, P. J. S. Williams, and M. Lockwood, Observations of large field-aligned flows of thermal plasma in the auroral ionosphere, Adv. Space Res., 9, 57, 1989. 